\title{
PERANCANGAN ONLINE MARKEPLACE UNTUK DEVELOPER PERUMAHAN DI KOTA BENGKULU
}

\author{
Asnawati $^{1}$, Khairil ${ }^{2}$, Ricky Zulfiandry ${ }^{3}$ \\ ${ }^{1,23}$ Dosen Tetap Program Studi Sistem Informasi Fakultas Ilmu Komputer Universitas Dehasen Bengkulu \\ Jl. Meranti Raya No. 32 Kota Bengkulu 38228 Telp. (0736) 22027, 26957 Fax. (0736) 341139; \\ e-mail: asna_pkg@yahoo.co.id khairil35@gmail.com, ricky.zulfiandry@unived.ac.id
}

\begin{abstract}
A$ residential property business is an activity in which a person invests in one or more houses, which in its implementation does not use production costs. Because it does not use its own production costs, it is certainly very safe for business people to control it, and the results can be taken at any time later in the form of profits. At present, housing businesses generally still market their products manually, namely through face-to-face (coming directly to the marketing place) to provide information to consumers about the housing sold by the developer. The online marketplace application for housing developers in Bengkulu City is a medium that can be used by developers to market the housing they manage, and also to provide information to the public about housing in Bengkulu City. The domain of this online marketplace application can be accessed through www.olmarketplacedevperumahan.online. In this online marketplace application there are 3 access rights from the application, namely the administrator (can manage the type of housing, and data developer in Bengkulu City), the developer (can update the data developer, and manage housing data), and the community (can see developer information, housing, and installment simulations). In order for developers to access this online marketplace application, developers must register with APERSI directly by attaching a profile from the developer. Then from APERSI will provide a username and password to the developer, so that developers can access this online marketplace application.
\end{abstract}

Keywords: Online Marketplace, Housing Developer, Bengkulu City

Intisari-Bisnis properti perumahan ialah suatu aktivitas di mana seseorang melakukan investasi pada satu rumah atau lebih, yang dalam pelaksanaannya tidak menggunakan biaya produksi. Karena tidak menggunakan biaya produksi sendiri, tentu sangat aman bagi para pelaku bisnis untuk mengontrolnya, dan hasilnya dapat diambil sewaktu-waktu di kemudian hari dalam bentuk keuntungan. Saat ini, para pelaku bisnis perumahan pada umumnya masih memasarkan produk secara manual yaitu melalui tatap muka (datang langsung ke tempat pemasaran) untuk memberikan informasi kepada konsumen tentang perumahan yang dijual oleh developer.

Aplikasi online marketplace untuk developer perumahan di Kota Bengkulu merupakan suatu media yang dapat digunakan oleh developer untuk memasarkan perumahan yang dikelolanya, dan juga untuk memberikan informasi kepada masyarakat tentang perumahan yang terdapat di Kota Bengkulu. Adapun domain dari aplikasi online marketplace ini dapat diakses melalui www.olmarketplacedevperumahan.online. Pada aplikasi online marketplace ini terdapat 3 hak akses dari aplikasi, yaitu administrator (dapat mengelola jenis perumahan, dan data developer di Kota Bengkulu), developer (dapat meng-update data developer, dan mengelola data perumahan), dan masyarakat (dapat melihat informasi developer, perumahan, serta simulasi cicilan). Agar developer dapat mengakses aplikasi online marketplace ini, developer harus mendaftarkan diri ke APERSI secara langsung dengan melampirkan profil dari developer. Kemudian dari pihak APERSI akan memberikan username dan password ke developer, sehingga developer dapat mengakses aplikasi online marketplace ini

Kata Kunci : Online Marketplace, Developer Perumahan, Kota Bengkulu

\section{PENDAHULUAN}

Dalam kehidupan sehari-hari teknologi informasi merupakan hal yang sangat berguna, dengan adanya informasi maka akan membantu kita untuk mengambil suatu keputusan dengan lebih tepat berdasarkan data-data yang diperoleh dalam bentuk informasi.

Di dalam dunia bisnis dewasa ini peranan internet telah dirasakan semakin penting dan berarti, karena dengan melalui internet pula para pelaku bisnis dapat melakukan transaksi bisnisnya secara online dimanapun berada. Tanpa adanya internet, para pelaku bisnis yang terpisah oleh jarak dan waktu dapat dipastikan akan mengalami masalah dan kesulitan dalam hal waktu dan biaya di dalam melakukan transaksi bisnisnya.

Bisnis properti perumahan ialah suatu aktivitas di mana seseorang melakukan investasi pada satu rumah atau lebih, yang dalam pelaksanaannya tidak menggunakan biaya produksi. Karena tidak menggunakan biaya produksi sendiri, tentu sangat aman bagi para pelaku bisnis untuk mengontrolnya, dan hasilnya dapat diambil sewaktu-waktu di kemudian hari dalam bentuk keuntungan. 
Saat ini, para pelaku bisnis perumahan pada umumnya masih memasarkan produk secara manual yaitu melalui tatap muka (datang langsung ke tempat pemasaran) untuk memberikan informasi kepada konsumen tentang perumahan yang dijual oleh developer.

Untuk membantu para developer khususnya di Bengkulu dalam memasarkan perumahan yang dikelolanya, maka penulis membuat suatu aplikasi online marketplace, dimana akan terdapat 3 antarmuka pada aplikasi tersebut yaitu administrator, developer, konsumen. Dengan adanya aplikasi ini diharapkan dapat membantu memasarkan perumahan pada masing-masing developer dan dapat memberikan informasi kepada konsumen tentang perumahan.

Berdasarkan uraian tersebut, penulis tertarik untuk mengangkat judul tentang "Perancangan Online Marketplace Untuk Developer Perumahan di Kota Bengkulu”.

\section{TINJAUAN PUSTAKA}

\section{Pengertian Perancangan}

Pengertian rancang adalah proses menganalisa kebutuhan dan mendeskripsikan dengan detail komponenkomponen yang akan di implementasi. Pengertian dari bangun yaitu menciptakan sistem baru atau memperbaiki sistem yang sudah ada [1]

\section{E-Market Place}

Dunia maya yang tercipta karena berkembangnya teknologi internet, secara tidak langsung membentuk sebuah pasar atau arena perdagangan tersendiri yang kerap dinamakan sebagai e-Marketplace (beberapa praktisi manajemen menyebutnya sebagai Marketspace). Sebagaimana pasar dalam pengertian konvensional, yaitu tempat bertemunya penjual dan pembeli, di dalam eMarketplace berinteraksi pula berbagai perusahaanperusahaan di dunia tanpa dibatasi oleh teritori ruang (geografis) maupun waktu. Beragam produk dan jasa dalam berbagai bentuknya dicoba ditawarkan oleh perusahaanperusahaan yang telah "go internet" ini dalam berbagai domain industri, sehingga menghasilkan suatu nilai dan volume perdagangan yang tidak kalah besar dari pasar konvensional [2].

\section{Bahasa Pemrograman PHP}

PHP (Hypertext Preprocessor), merupakan bahasa pemrograman pada sisi server yang memperbolehkan programmer menyisipkan perintah - perintah perangkat lunak web server (Apache, IIS, atau apapun) akan dieksekusi sebelum perintah itu dikirim oleh halaman ke browser yang me-request-nya, contohnya adalah bagaimana memungkinkannya memasukkan tanggal sekarang pada sebuah halaman web setiap kali tampilan tanggal dibutuhkan. Sesuai dengan fungsinya yang berjalan di sisi server maka PHP adalah bahasa pemrograman yang digunakan untuk membangun teknologi web application. [3].

PHP telah menjadi bahasa scripting untuk keperluan umum yang pada awalnya hanya digunakan untuk pembangunan web yang menghasilkan halaman web dinamis. Untuk tujuan ini, kode PHP tertanam ke dalam dokumen sumber HTML dan diinterpretasikan oleh server web dengan modul PHP prosesor, yang menghasilkan dokumen halaman web. Sebagai bahasa pemrograman untuk tujuan umum, kode PHP diproses oleh aplikasi penerjemah dalam modus baris - baris perintah modus dan melakukan operasi yang diinginkan sesuai sistem operasi untuk menghasilkan keluaran program di channel output standar. Hal ini juga dapat berfungsi sebagai aplikasi grafis. PHP tersedia sebagai prosesor untuk server web yang paling modern dan sebagai penerjemah mandiri pada sebagian besar system operasi dan komputer platform

4. MySQL

MySQL adalah sebuah implementasi dari sistem manajemen basis data relasional (RDBMS) yang didistribusikan secara gratis di bawah lisensi GPL (General Public License). Setiap pengguna dapat secara bebas menggunakan MySQL, namun dengan batasan perangkat lunak tersebut tidak boleh dijadikan produk turunan yang bersifat komersial. MySQL sebenarnya merupakan turunan 
salah satu konsep utama dalam basis data yang telah ada sebelumnya SQL (Structured Query Language). SQL adalah sebuah konsep pengoperasian basis data, terutama untuk pemilihan atau seleksi dan pemasukan data, yang memungkinkan pengoperasian data dikerjakan dengan mudah secara otomatis [3].

\section{Adobe Dreamweaver CC 2015}

Adobe Dreamweaver merupakan aplikasi pengembang yang berfungsi untuk mendesain web yang dibuat, dikembangkan, dan diproduksi oleh Adobe System. Aplikasi pengembang web ini sangat digemari oleh web desainer dalam merancang web sebab perangkat lunak komputer ini memiliki kelebihan dan kemudahan dalam penggunaannya. Dengan menggunakan aplikasi ini, pengembangan web dapat dilakukan secara visual, sehingga hasil perancangan web dapat langsung terlihat tanpa harus menggunakan aplikasi bantu peramban seperti Google Chrome, Firefox atau Internet Explorer. Teknologi web yang didukung oleh Adobe Dreamweaver sangat beragam, salah satunya adalah teknologi untuk kebutuhan pengembangan web berbasis mobile.[4]

\section{Diagram Alir Data}

Diagram Arus Data atau yang sering disebut sebagai Data Flow Diagram (DFD) merupakan alat perancangan sistem yang berorientasi pada alur data dengan konsep dekomposisi dapat digunakan untuk penggambaran analisa maupun rancangan sistem yang mudah dikomunikasikan oleh profesional sistem kepada pemakai maupun pembuat program. Diagram Arus Data mempunyai empat komponen utama yaitu entitas (entities), proses (process), media penyimpanan (data storage) dan arus data (data flows). Ke empat komponen tersebut menggambarkan arus sistem agar mudah dipahami [5].

\section{Entity Relationship Diagram}

Entity Relationship Diagram (ERD) data model didasarkan pada persepsi terhadap dunia nyata yang tersusun atas kumpulan objek-objek dasar yang disebut entitas dan hubungan antar objek. Entitas adalah sesuatu atau objek dalam dunia nyata yang dapat dibedakan dari objek lain. Misal: mahasiswa, dan matakuliah. Entitas digambarkan dalam basis data dengan kumpulan atribut. Misalnya: nim, nama, alamat, dan kota. Relasi adalah hubungan antara beberapa entitas. Misalnya: relasi menghubungkan mahasiswa dengan mata kuliah yang diambilnya [5].

\section{METODOLOGI PENELITIAN}

1. Metode Pengumpulan Data

Metode pengumpulan data yang digunakan dalam penelitian ini, antara lain :

a. Studi Pratikum

Studi praktikum adalah merancang aplikasi online marketplace untuk developer perumahan di Kota Bengkulu. Studi praktikum dilakukan dengan menguji coba aplikasi dengan memberikan masukan input untuk mengetahui apakah aplikasi sudah berjalan dengan semestinya.

b. Studi Pustaka

Studi pustaka adalah suatu metode pengumpulan data yang diambil dari perpustakaan atau instansi yang berupa karya ilmiah, jurnal, buku-buku yang berhubungan dengan penulisan ini.

2. Analisis Sistem Aktual

Bisnis properti perumahan ialah suatu aktivitas di mana seseorang melakukan investasi pada satu rumah atau lebih, yang dalam pelaksanaannya tidak menggunakan biaya produksi. Karena tidak menggunakan biaya produksi sendiri, tentu sangat aman bagi para pelaku bisnis untuk mengontrolnya, dan hasilnya dapat diambil sewaktu-waktu di kemudian hari dalam bentuk keuntungan. Saat ini, para pelaku bisnis perumahan pada umumnya masih memasarkan produk secara manual yaitu melalui tatap muka (datang langsung ke tempat pemasaran) untuk memberikan informasi kepada konsumen tentang perumahan yang dijual oleh developer.

\section{Analisis Sistem Baru}

Untuk membantu para developer khususnya di Bengkulu dalam memasarkan perumahan yang dikelolanya, 
maka penulis membuat suatu aplikasi online marketplace, dimana akan terdapat 3 antarmuka pada aplikasi tersebut antara lain :

a. Administrator dapat mengelola data developer dan data jenis perumahan yang ada di Kota Bengkulu.

b. Developer dapat meng-update data developer dan juga dapat mengelola data perumahan yang akan dipasarkan

c. Konsumen dapat mengetahui informasi perumahan yang terdapat di Kota Bengkulu.

Dengan adanya aplikasi ini diharapkan dapat membantu memasarkan perumahan pada masing-masing Developer dan dapat memberikan informasi kepada konsumen tentang perumahan

\section{Diagram Alir Data}

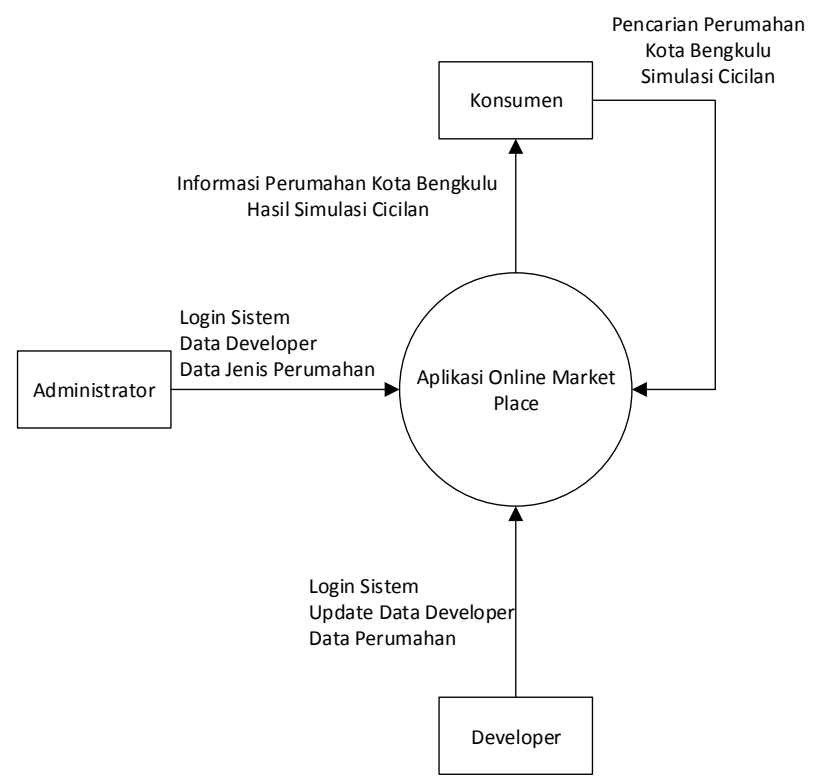

Gambar 1. Diagram Konteks

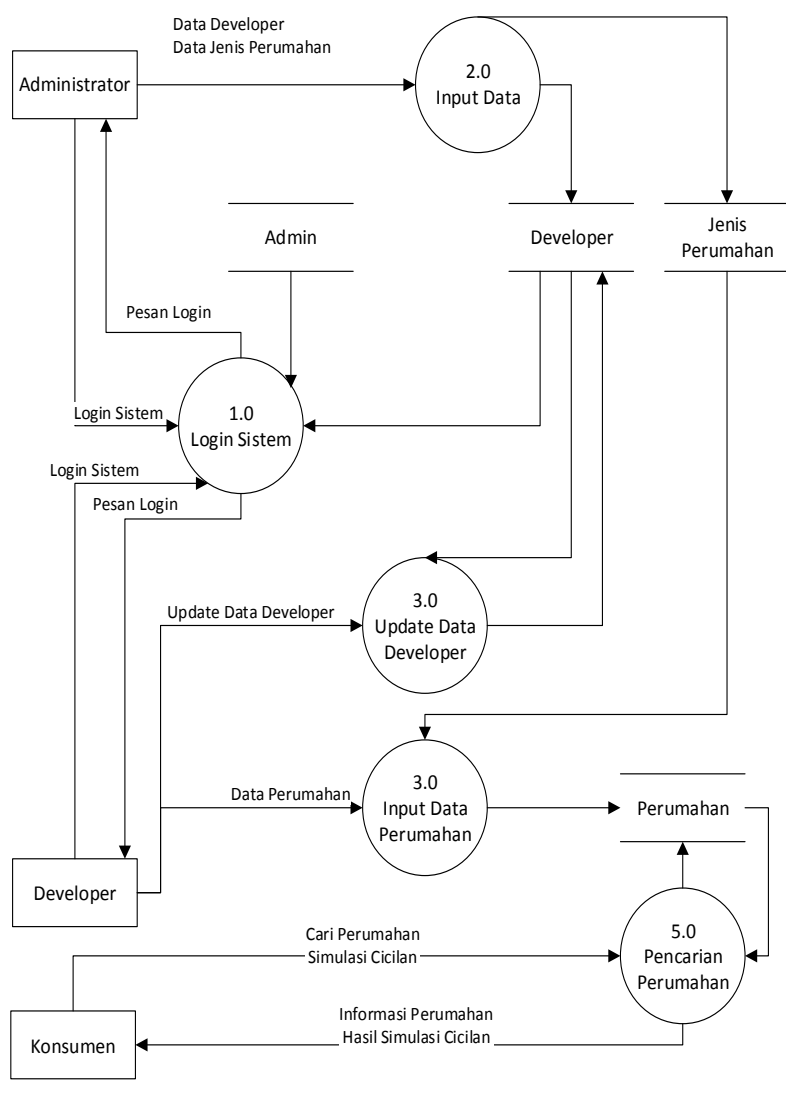

Gambar 2. DAD Level 0

5. Entity Relationship Diagram

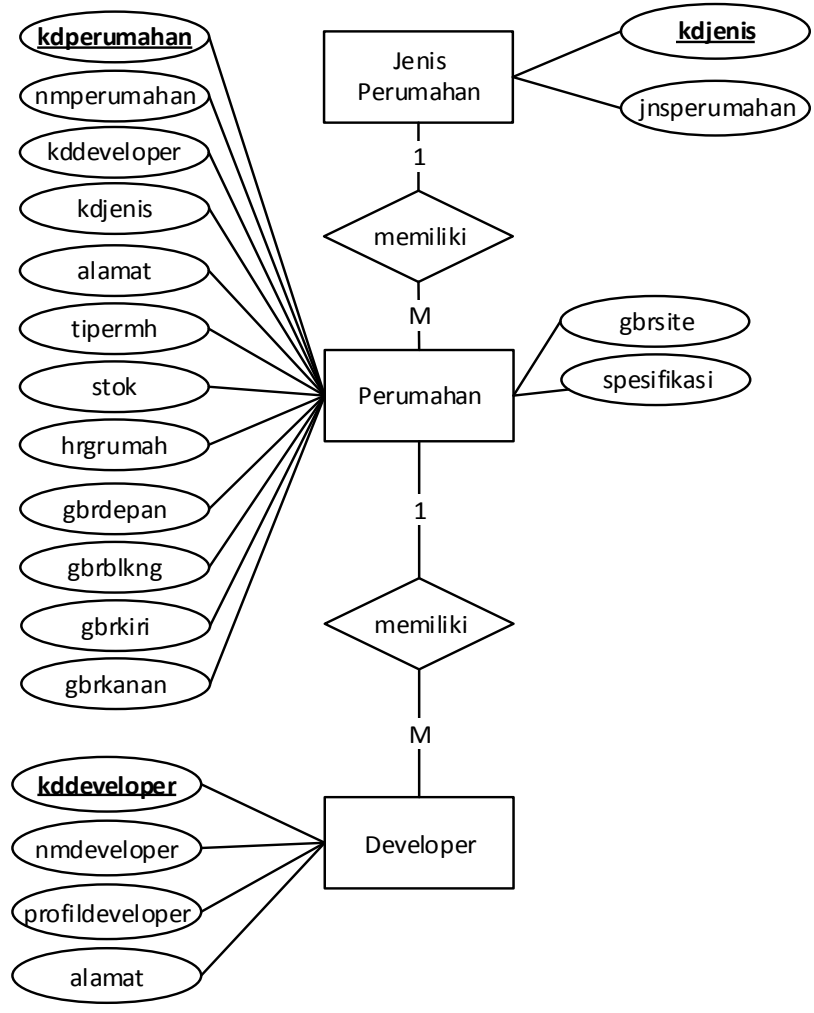

Gambar 3. ERD 


\section{HASIL DAN PEMBAHASAN}

Aplikasi online marketplace untuk developer perumahan di Kota Bengkulu merupakan suatu media yang dapat digunakan oleh developer untuk memasarkan perumahan yang dikelolanya, dan juga untuk memberikan informasi kepada masyarakat tentang perumahan yang terdapat di Kota Bengkulu.

Pada aplikasi online marketplace ini terdapat 3 hak akses dari aplikasi, yaitu administrator (dapat mengelola jenis perumahan, dan data developer di Kota Bengkulu), developer (dapat meng-update data developer, dan mengelola data perumahan), dan masyarakat (dapat melihat informasi developer, perumahan, serta simulasi cicilan).

Agar developer dapat mengakses aplikasi online marketplace ini, developer harus mendaftarkan diri ke APERSI secara langsung dengan melampirkan profil dari developer. Kemudian dari pihak APERSI akan memberikan username dan password ke developer, sehingga developer dapat mengakses aplikasi online marketplace ini.

Aplikasi online marketplace ini dapat diakses melalui url : http://www.olmarketplacedevperumahan.online,

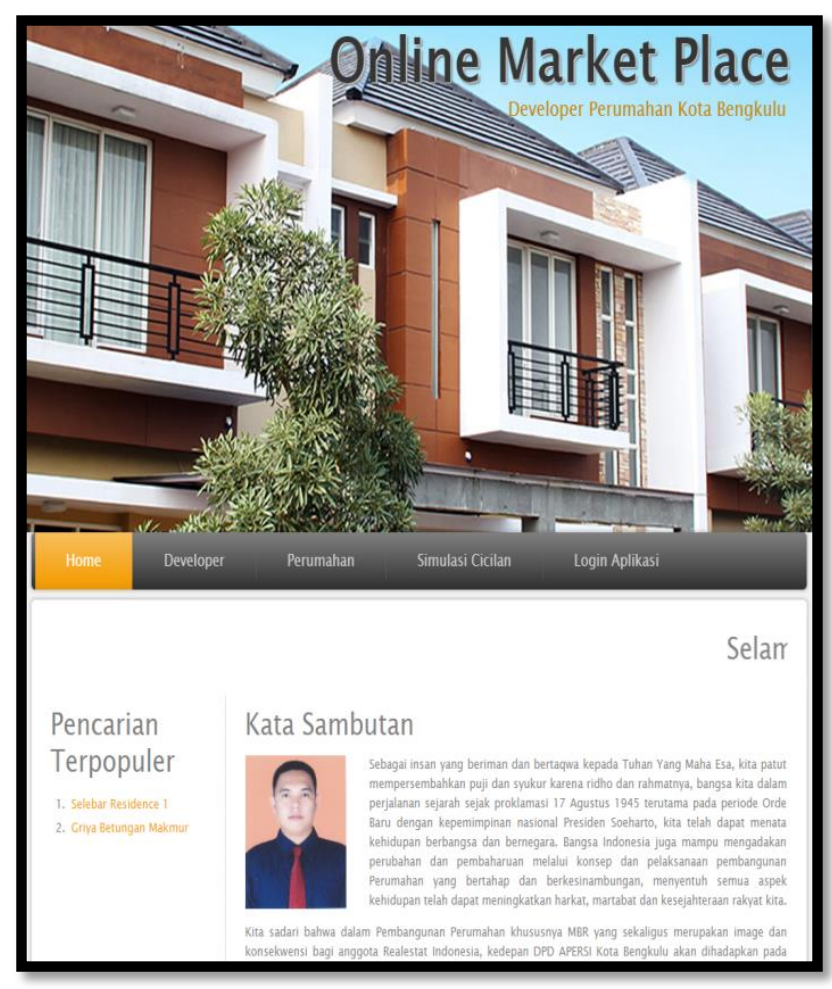

Gambar 4. Homepage
Agar dapat masuk ke halaman administrator, admin harus melakukan login pada form login yang telah disediakan.

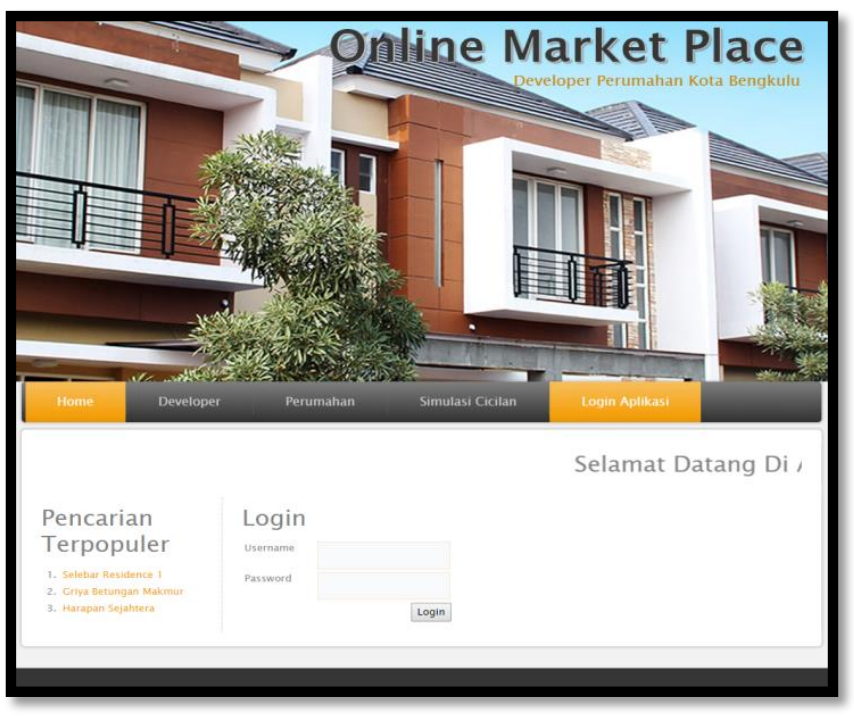

Gambar 5. Login

Halaman input data jenis perumahan merupakan antarmuka dari aplikasi yang dapat digunakan untuk mengolah data jenis perumahan yang terdapat di Kota Bengkulu, sebagai contoh subsidi, komersial.

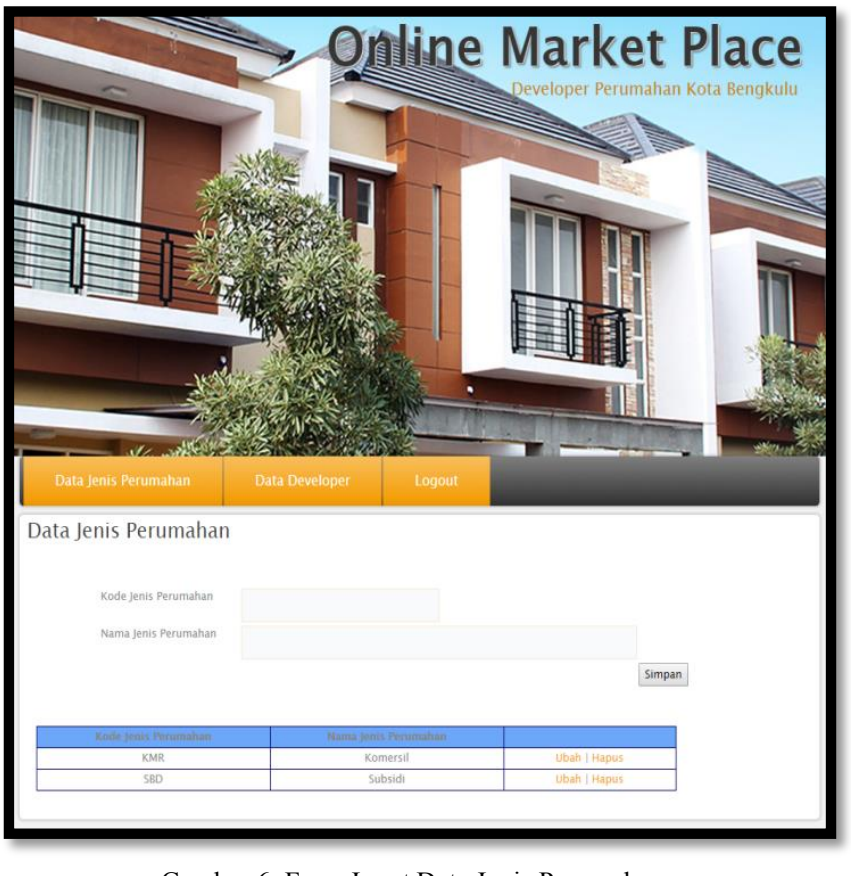

Gambar 6. Form Input Data Jenis Perumahan

Halaman input data developer merupakan antarmuka dari aplikasi yang dapat digunakan untuk mengolah data developer yang telah mendaftarkan diri ke APERSI, dimana admin akan membuat username dan password yang 
nantinya diberikan ke developer, agar developer dapat mengakses aplikasi.

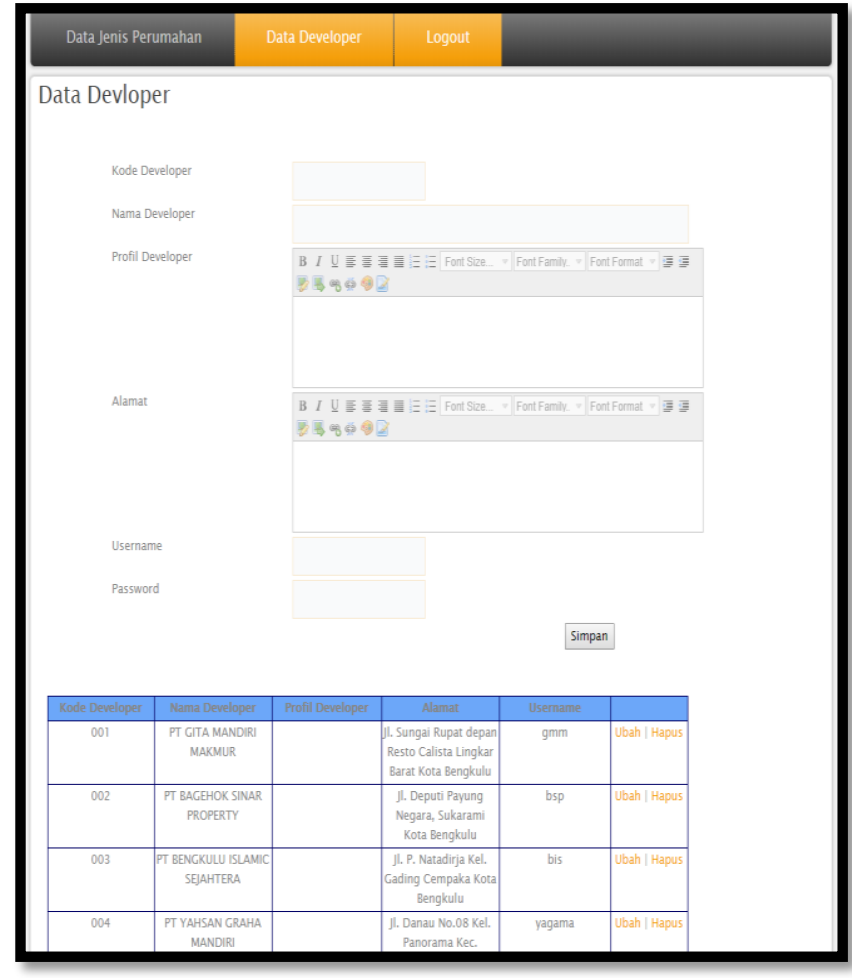

Gambar 7. Form Input Data Developer

Agar dapat masuk ke halaman developer, operator developer harus melakukan login pada form login yang telah disediakan.

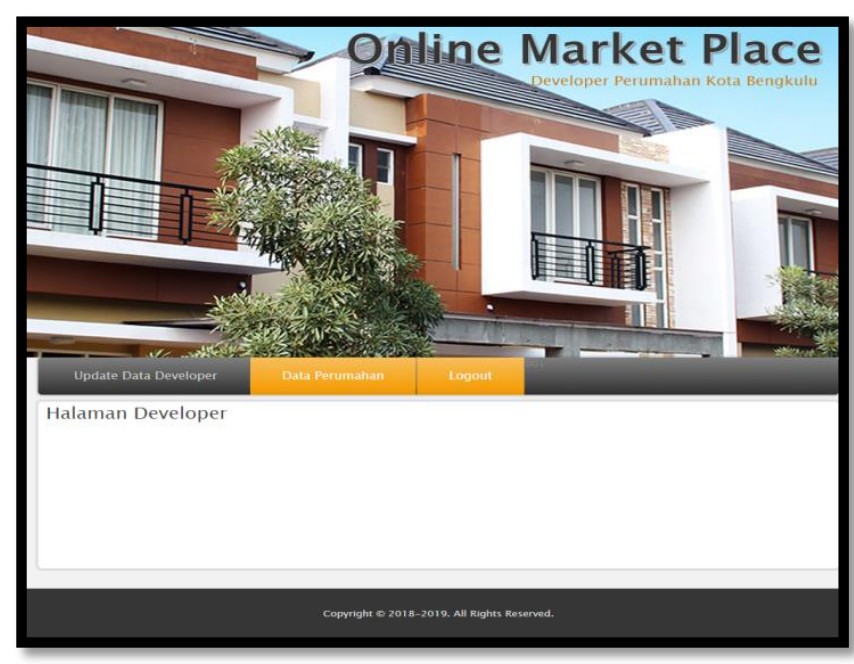

Gambar 8. Developer

Halaman update data developer merupakan antarmuka dari aplikasi yang dapat digunakan untuk mengubah data developer, dari profil hingga username dan password dari developer.

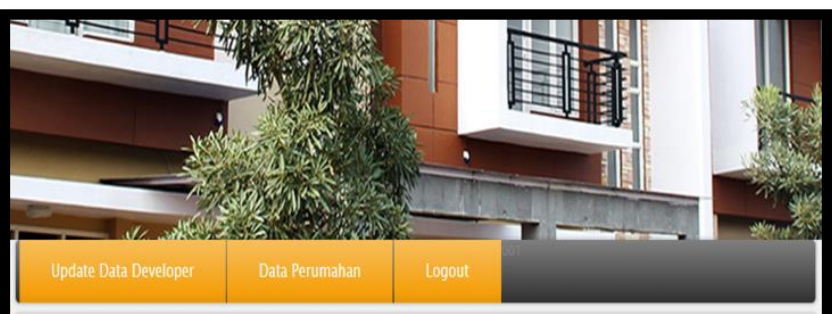

Data Jenis Perumahan

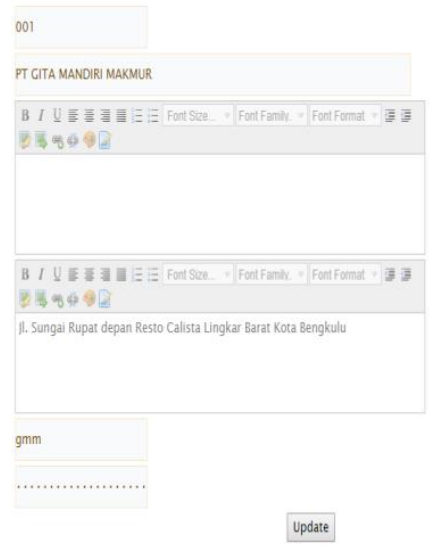

Gambar 9. Update Data

Halaman data perumahan merupakan antarmuka dari aplikasi yang dapat digunakan untuk mengolah data perumahan yang dikelola oleh developer

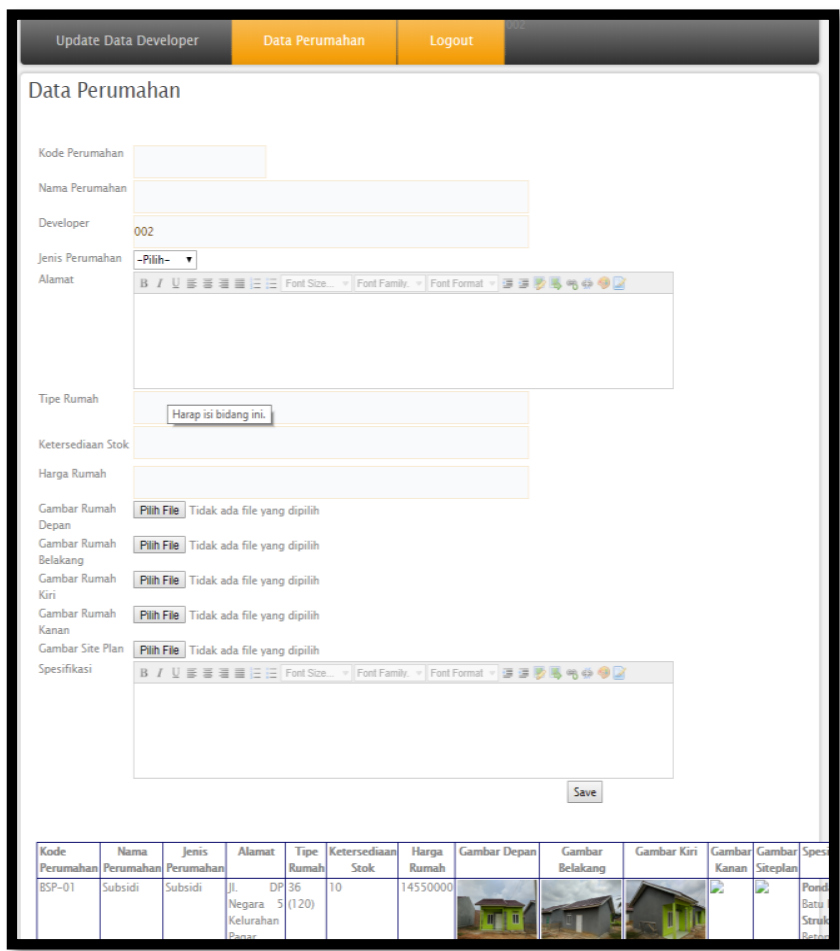

Gambar 10. Data Perumahan 
Home merupakan antarmuka aplikasi yang muncul ketika membuka url website aplikasi.

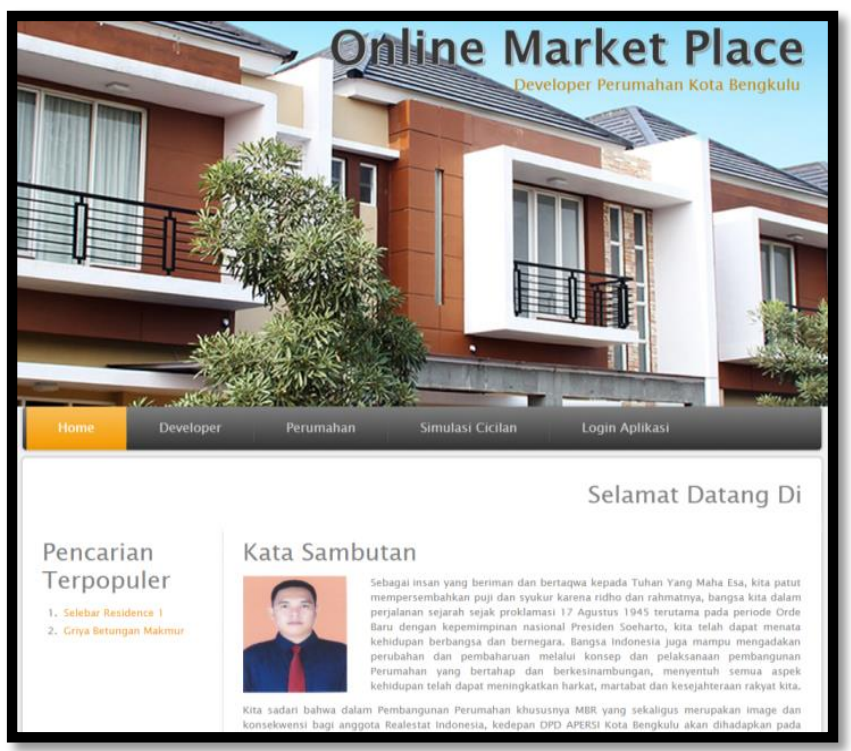

Gambar 11. Masyarakat

Developer merupakan antarmuka aplikasi yang dapat digunakan oleh masyarakat untuk mengetahui informasi dari developer perumahan di Kota Bengkulu

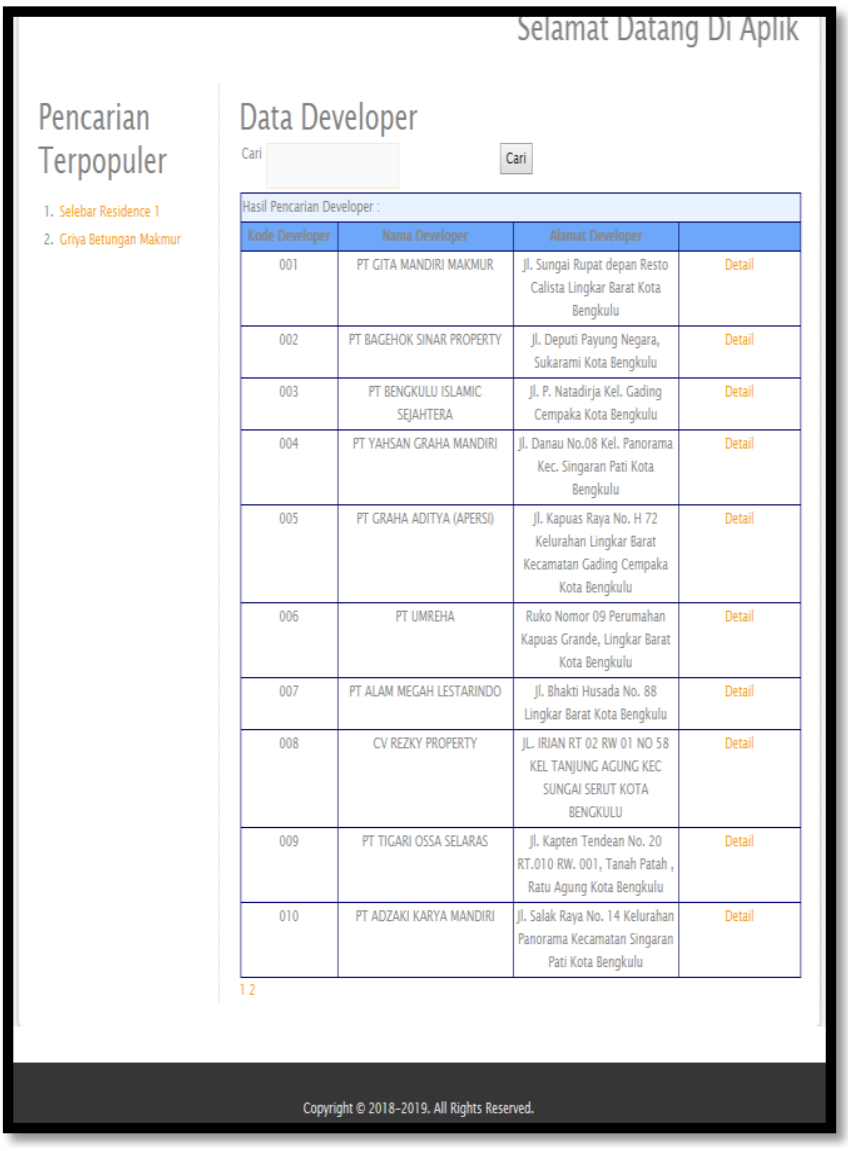

Gambar 12. Data Developer
Perumahan merupakan antarmuka aplikasi yang dapat digunakan oleh masyarakat untuk mengetahui informasi dari perumahan yang terdapat di Kota Bengkulu

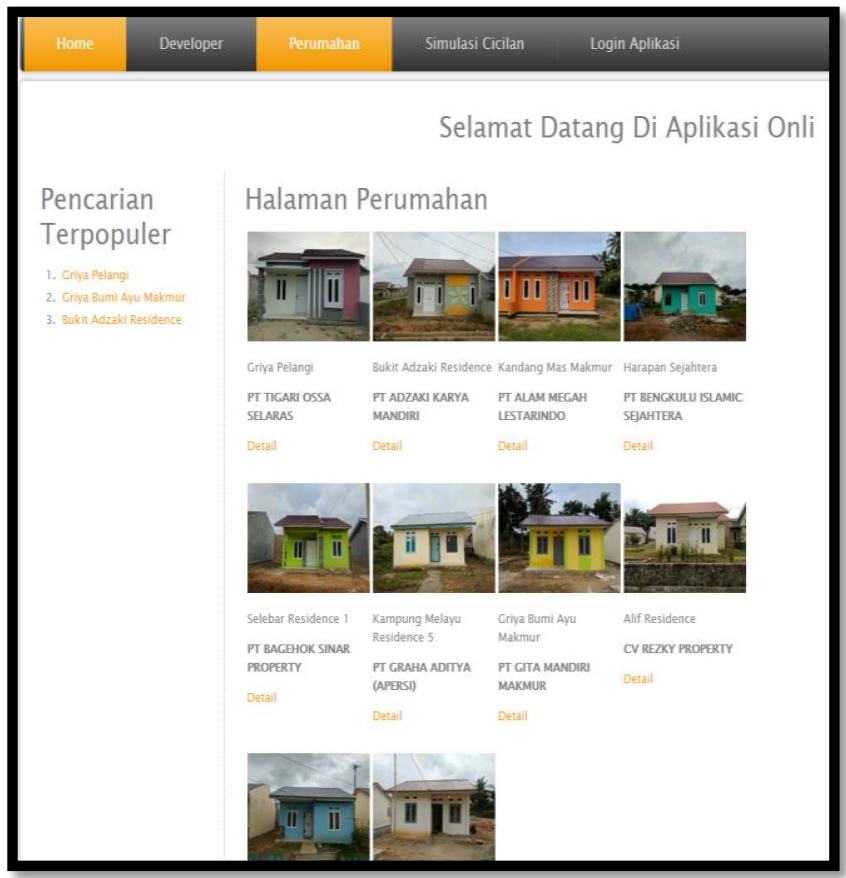

Gambar 13. Data Perumahan

Terdapat pencarian yang dapat dilakukan oleh masyarakat, dan juga terdapat link detail untuk melihat detail informasi perumahan di Kota Bengkulu.

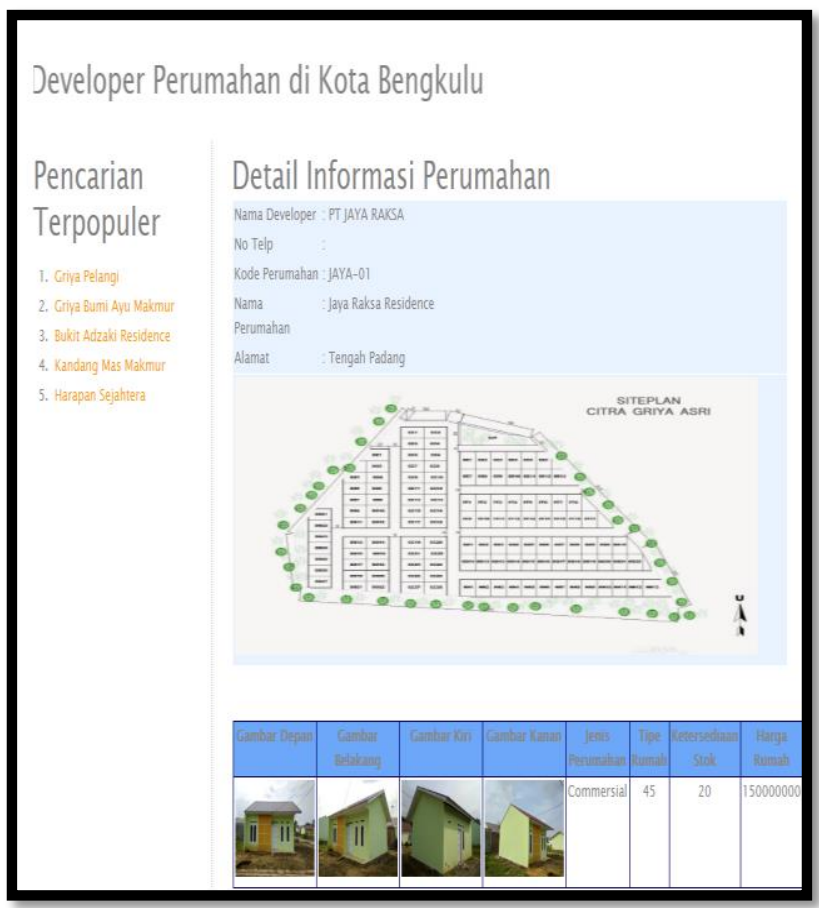

Gambar 14. Data Detail Perumahan 
Simulasi cicilan merupakan antarmuka aplikasi yang dapat digunakan oleh masyarakat untuk memberikan informasi cicilan perumahan jika memasukkan down payment (DP). dalam proses hasil cicilan ini menggunakan persentase yang didapat dari bank BTN dimana bunga untuk perumahan subsidi 5\% dan komersial $12 \%$.

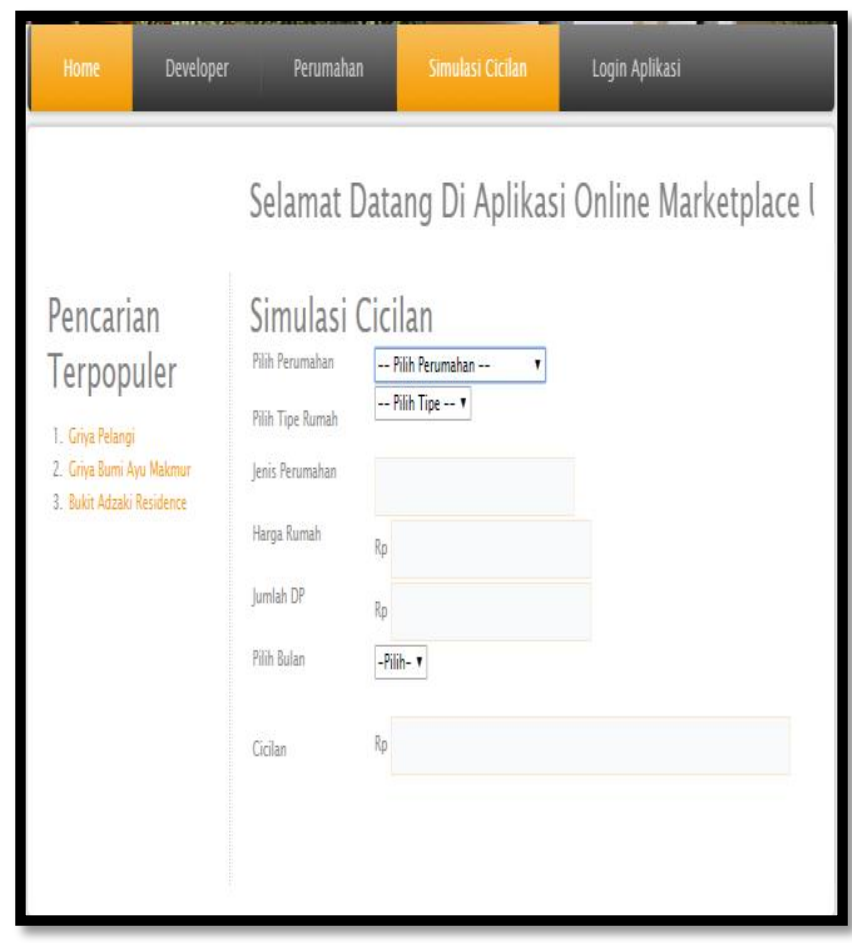

Gambar 15. Data Simulasi Cicilan

\section{KESIMPULAN DAN SARAN}

1. Kesimpulan

Berdasarkan hasil dari pembahasan tersebut, maka dapat disimpulkan bahwa :

1. Aplikasi online marketplace untuk developer perumahan di Kota Bengkulu merupakan suatu media yang dapat digunakan oleh developer untuk memasarkan perumahan yang dikelolanya, dan juga untuk memberikan informasi kepada masyarakat tentang perumahan yang terdapat di Kota Bengkulu.

2. Aplikasi online marketplace ini dapat diakses melalui www.olmarketplacedevperumahan.online

3. Pada aplikasi online marketplace ini terdapat 3 hak akses dari aplikasi, yaitu administrator (dapat mengelola jenis perumahan, dan data developer di Kota Bengkulu), developer (dapat meng-update data developer, dan mengelola data perumahan), dan masyarakat (dapat melihat informasi developer, perumahan, serta simulasi cicilan).

4. Agar developer dapat mengakses aplikasi online marketplace ini, developer harus mendaftarkan diri ke APERSI secara langsung dengan melampirkan profil dari developer. Kemudian dari pihak APERSI akan memberikan username dan password ke developer, sehingga developer dapat mengakses aplikasi online marketplace ini.

2. Saran

Berdasarkan penelitian yang penulis lakukan, maka penulis menyarankan untuk menggunakan aplikasi online marketplace ini agar dapat membantu pemasaran perumahan yang terdapat di Kota Bengkulu.

\section{DAFTAR PUSTAKA}

[1] Adipranata, Rudy. Dkk. 2015. E-Market Place Sebagai Sarana Transaksi Lelang Online. fportfolio.petra.ac.id

[2] Februariyanti, Herny. Zuliarso, Eri. 2012. Rancang Bangun Sistem Perpustakaan Untuk Jurnal Elektronik. Jurnal Teknologi Informasi DINAMIK Vol.17 No.2 Juli 2012. ISSN : 0954-9524..

[3] Hidayatullah, Priyanto. Kawistara, Jauhari Khairul. 2017. Pemrograman Web Edisi Revisi. Penerbit Informatika : Bandung.

[4] Kodong, Frans Richard. Dkk. 2012. Model Aplikasi E-Market Sebagai Sarana Promosi dan Tukar Menukar Informasi Antara Penjual dan Pembeli. Jurnal Telematika Vol.8 No.2 Januari 2012

[5] Sutabri, Tata. 2012. Analisis Sistem Informasi. Penerbit Andi : Yogyakarta. 